\title{
Anticipatory Bail and Criminal Justice in India
}

\author{
Prof. Pradeep Singh \\ Professor \\ Faculty of Law \\ Banaras Hindu University \\ Varanasi, UP, India \\ E-MAIL: pradeep@bhu.ac.in \\ India
}

\begin{abstract}
A R T I C L E I N F O
Article history: Article

Received

Revised : 8 December 2020

Accepted: 15 December 2020

DOI: $10.47742 /$ ijbssr.v1n4p1
\end{abstract}

Vol: 1, Issue: 4

December/2020

https://ijbssrnet.com/index.php/ijbssr DOI: 10.47742/ijbssr.v1n4p1

\begin{abstract}
A B S T R A C T
Social reputation and personal liberty are two important things in life human beings which are most dear and most respected. Whenever any person has enmity with another person, he tries to affect the social reputation and personal liberty of later person and usually for the purpose criminal justice system is misused. Vested interests file the false case, thereby, the alleged person may be arrested and kept in custody which may cause a loss of reputation and personal liberty of the alleged person. Such misuse of the criminal justice system is a reality. Therefore, it is the responsibility of the criminal justice system itself to protect innocent persons falsely alleged in a criminal case. Indian criminal justice system has prescribed anticipatory bail to protect the falsely alleged person. This article will analyze the legal regime provided in the Indian criminal justice system about anticipatory bail.
\end{abstract}

Keywords: Anticipatory bail, Arrest, bail, crime, criminal justice system, custody, personal liberty, society.

\section{Introduction}

The Criminal Justice system functions to tackle criminality, thereby, ultimately to protect society and whole humanity against the impacts of criminality. For the aforesaid, proper case must be investigated and tried by investigating agency and trial authority respectively. Investigation and trial can be properly accomplished in presence of the accused person and for it accused has to be taken in the custody. In the Indian criminal justice system, the legally accused person is presumed as an innocent person but in common mass in Indian society considers and treats a person as criminal as soon as the accused is arrested and taken into custody. It may be decided that whether the accused committed a crime or not, on the conclusion of trial but the common mass considers him criminal with his arrest. It is history and also it is, in reality, happening presently in India that some vested interests, to affect the reputation of the person to whom he is feeling enmity, files the false case, thereby such alleged person may be arrested and may lose his reputation by being stigmatized and labeled as a criminal. Further, the accused is not convicted and sentenced, even after that keeping him in custody causes interference with his liberty. It is greater responsibility imposed on the criminal justice system to protect the accused person from losing his reputation and personal liberty only on being falsely alleged in the case or when there is no need of keeping the accused in the custody. Indian criminal justice system by prescription of a special kind of bail has provided the solution of aforesaid problems, and thereby, has extended protection to innocent persons from losing reputation and personal liberty by being falsely alleged in the criminal case.

Bail granted by Court of Session and High Court u/s 438 Criminal Procedure Code 1973 (hereinafter referred as CrPC) is called anticipatory bail, normally, bail is granted after the arrest of the person while the person, in whose favor bail direction is issued, is in custody or otherwise, such person comes in custody but the bail direction u/s $438 \mathrm{CrPC}$ is issued in anticipation of arrest and anticipation of custody, therefore, name anticipatory bail is used for this bail direction. Anticipatory bail is granted before the arrest of the person; it means at the time of grant of anticipatory bail direction the person for whose bail such direction is going to be issued must not be in the custody. The provisions provided in Section $438 \mathrm{CrPC}$ are applicable only before the arrest and/or custody of the person; as soon as the person is arrested or otherwise comes into custody, section 438 CrPC ceases to apply. A person who has reason to fear or suspect that he may be arrested on a false accusation may apply for anticipatory bail direction $\mathrm{u} / \mathrm{s} 438 \mathrm{CrPC}$ that in case of arrest he be released on bail. In the Code of 1898, there was no provision for the grant of anticipatory bail. For the first time, the 41 st Law Commission report recommended for inclusion of provisions for anticipatory bail direction in CrPC. Law commission made its recommendation on two grounds -

1. In Indian society, there has been a history of misuse and abuse of criminal proceedings. Notorious persons and criminals do not have a problem in arrest and putting in jail, it may augment their name in the criminal world but 
https://ijbssrnet.com/index.php/ijbssr DOI: 10.47742/ijbssr.v1n4p1

when sober and civilized persons are alleged for some crime commission and particularly when arrested by police and kept in jail, his and his family reputation is completely affected and shattered. Stronger persons particularly politically and economically, try to file a false case against a weaker person only with the purpose that he be arrested and put in custody for few days so that he may lose his and his family reputation. Further such false case filing, consequential arrest, and custody are used to exploit, harass, and pressurize weaker persons. There is a need to protect the common person from going to jail in false cases, thereby, to protect the reputation of such a person. Law Commission recommended that for protection of the weaker person against the misuse of criminal procedure by a stronger person, there should be a measure of anticipatory bail.

2. A person who is put in custody is accused, he is not a convict, only to ascertain his fitness for bail, and thereby, his behavior about requirements of criminal justice, he is arrested, otherwise accused is considered as an innocent person. As soon as it is identified that he is fit for bail, bail is granted. Law Commission recommended that if the fitness of a person can be decided before the arrest of the person then what is need to have the formality of his arrest, let remain him in jail for some days and then on his application consider about his fitness for bail. It may be better than the fitness of a person should be decided before his arrest, and if he is fit immediately he should be released and there should not be the formality of arrest and kept in custody for some days then granting bail.

In Gurbaksh Singh Sibbia v. State of Punjab ${ }^{l}$ Supreme Court differentiated anticipatory bail from regular bail by giving observation - 'the distinction between an ordinary order of bail and an order of anticipatory bail is that whereas the former is granted after arrest and therefore means release from the custody of the police, the latter is granted in anticipation of arrest and is therefore effective at the very moment of arrest'. Law Commission to differentiate this kind of grant of bail which is provided before arrest and custody of the person from bail provided after coming in custody used term anticipatory bail. But this name is considered a misnomer and usually creates confusion. In Section $438 \mathrm{CrPC}$ also names anticipatory bail is not used, neither used in the main provision nor marginal note of Section $438 \mathrm{CrPC}$. It is a fact that a person cannot be released on bail unless he is in custody. It is natural unless a person is deprived of his liberty, how can his liberty be restored by the release on bail. For the grant of bail, custody is an essential requirement. Anticipatory bail term refers to bail granting before arrest and custody, which is not permissible. A perusal of Section 438 particularly provisions contained in sub-section (1) and (3) of Section 438 clarifies the situation that the direction for bail is issued before arrest and custody but such direction becomes operational and the accused is released only after arrest and/or custody. In sub-section (1) of Section $438 \mathrm{CrPC}$, a person applies anticipatory bail direction through which he does not request for immediate bail but his request is for release on bail in event of his arrest. Further, in this connection sub-section (3) is material one which clears that anticipatory bail direction does not make the bar on arrest without warrant or with a warrant; only the fact is that the person as soon as comes in custody, he is released on bail. It means the person in whose favor anticipatory bail direction is issued may be arrested but he shall not continue in the custody. In case of anticipatory bail fitness of a person is decided before arrest and custody, and he is released when he is arrested and as soon as custody initiates. Thereby in anticipatory bail also bail becomes operational when custody initiates. Anticipatory bail is different from regular bail in that fitness for bail and direction for bail is decided before arrest and custody while in regular bail fitness for bail is determined after a person coming into custody but in both cases bails become operational when the person to be released is in custody. Therefore, the anticipatory bail term is a misnomer; actually, it is not anticipatory bail but the anticipatory direction for bail to become operational with custody of the person. Anticipatory bail is a misnomer but by tradition, this name is used to denote bail granted under Section $438 \mathrm{CrPC}$. Section 438 (1) CrPC consists of main provisions relating to anticipatory bail, which provides:

"Where any person has reason to believe that he may be arrested on accusation of having committed a non-bailable offense, he may apply to the High Court or the Court of Session for a direction under this section that on in the event of such arrest he shall be released on bail; and that Court may after taking into consideration, inter alia, the following factors, namely..."

2.Anticipatory bail is not a shield for commission for crime

Anticipatory bail is an extra-ordinary remedy as a normal issue relating to bail is decided after arrest while accused is in custody but in case of anticipatory bail fitness of a person for bail is decided before his coming in custody and direction for release in event of his arrest is passed before his arrest. Therefore, about anticipatory bail $\mathrm{u} / \mathrm{s}, 438 \mathrm{CrPC}$ jurisdictions are conferred on the Court of Session and High Court which are superior courts in the criminal justice system. Court of Session and High Courts are superior courts and presided over by experienced judges who may be able to properly determine a person for bail even when the person is not in custody and the case may be in the very initial stage in the investigation. In Gurbaksh Singh Sibbia v. State of Punjab Supreme Court observed:

"...There is no risk involved in entrusting a wide discretion to the Court of Session and the High Court in granting anticipatory bail because, firstly, these are higher courts manned by experienced persons, secondly, their orders are not final but are open to appellate or revisional scrutiny and above all, because discretion has always to be exercised by courts judicially and not according to whim, caprice or fancy..." 


\section{Vol: 1, Issue: 4} December $/ 2020$

https://ijbssrnet.com/index.php/ijbssr DOI: 10.47742/ijbssr.v1n4p1

Anticipatory bail provision contained in Section 438 $\mathrm{CrPC}$ is applicable for non-bailable offense only. If it is compared with bail in case of bailable offenses, it may be found that after anticipatory bail direction in case of non-bailable offense situation of bail become similar to bail available in Section 436 $\mathrm{CrPC}$ that as soon as a person comes in custody he shall be released on bail. Due to Section $436 \mathrm{CrPC}$, there is no need for an anticipatory bail in case of bailable offense, therefore in Section 438 (1) CrPC, it is cleared that anticipatory bail direction is available only in case of non-bailable offenses. For anticipatory bail petition filing and issuance of direction $\mathrm{u} / \mathrm{s} 438 \mathrm{CrPC}$, there doesn't need to be a formal accusation, because the petition is moved when 'any person has reason to believe that he may be arrested on accusation of having committed a non-bailable offense'. An applicant for anticipatory bail applies based on his believing that he may be arrested on accusation of commission of non-bailable offense but such believing of a person cannot be subjective referring to mere fear or mere suspicion but must be based on the proper ground; it should not only be 'believe' but there must be 'reason to believe' for arrest. Sufficient material should be available in the case to show the move on part of the police officer or some person/persons to implicate him in a false case to get him arrested and put in custody. Implicitly "reason to believe' also includes the rule that the Court cannot grant a 'blanket order of anticipatory bail'. Reason to believe refers that person has sufficient material about a particular, specific, and definite case, already lodged or probable to be lodged, and only for that case applicant is requesting for issuance of anticipatory bail and only for such particular, specific, and definite case, Court grants anticipatory bail. The court cannot pass general anticipatory bail order. General anticipatory bail order means the order is passed for any case, any arrest, and to any person. Such order may be given even on mere suspicion of arrest, therefore, in such a situation any person may come and get an anticipatory bail protecting him from arrest, he may not available for any action. Such a person may get a license for the commission of the crime and even after that, he may not be available to law enforcement agencies as having a protective wrap of general anticipatory bail. Such general anticipatory direction is called 'blanket order of anticipatory bail'; it is not permissible u/s 438 CrPC. Only specific anticipatory bail order is issued u/s 438 CrPC. Anticipatory bail is not a shield or license for the commission of the crime and remains unavailable to the criminal justice system. Anticipatory bail is protection to innocent people from harassment, exploitation, and loss of reputation by falsely implicating in some cases, arrest, and lodging in custody. Blanket anticipatory bail is completely prohibited. In Gurbaksh Singh Sibbia v. State of Punjab Supreme Court observed that the court cannot issue blanket anticipatory bail order that the person shall be released on bail 'whenever arrested for whichever offense whatsoever':

"We agree that a 'blanket order' of anticipatory bail should not generally be passed. This flows from the very language of the section which, as discussed above, requires the applicant to show that he has "reason to believe" that he may be arrested. A belief can be said to be founded on reasonable grounds only if there is something tangible to go by based on which it can be said that the applicant's apprehension that he may be arrested is genuine. That is why, normally, a direction should not issue under S. 438 (1) to the effect that the applicant shall be released on bail "whenever arrested for whichever offense whatsoever". That is what is meant by a 'blanket order' of anticipatory bail, an order which serves as a blanket to cover or protect any and every kind of allegedly unlawful activity..."

Gurbaksh Singh Sibbia v. State of Punjab case was decided by the Constitutional Bench of Supreme Court. The case was filed as an appeal against the rejection of the anticipatory bail petition by the Full Bench of Punjab and Haryana High Court. Gurbaksh Singh Sibbia was Minister of Irrigation and Power in the Punjab Government. Against him grave charges of corruption were alleged, whereupon, he filed a petition before High Court requesting the issuance of anticipatory bail direction; Single Judge referred the matter to Full Bench of High Court which dismissed the petition. In the Supreme Court matter was considered by Constitutional Bench and settled the whole law relating to anticipatory bail. In this case, the Supreme Court decided that the applicant doesn't need to make a special case for grant of anticipatory bail; the only requirement is that he should show that anticipatory bail may be given. Supreme Court did not accept propositions of High Court and decide that whether anticipatory bail has to be given or not should be decided by courts by using their judicial discretion.

\section{Anticipatory bail is granted for a limited period}

In Gurbaksh Singh Sibbia v. State of Punjab Supreme Court implicitly cleared that person released on bail through anticipatory bail direction may be on bail for a longer period means it may be till cancellation of bail or disposal of the case. Theoretically, there is no limitation of time; it may e available as it is in the case of regular bail. but the court further observed that it would be better than it should be for a limited period and appropriate may be that it should be till filing of FIR and after that accused should submit himself before the court and get the regular bail. Anticipatory bail is given before lodging of FIR or in the very initial stage of the investigation. At this stage sufficient matter relating to the case and determination of fitness of bail may not be available, therefore, generally, it may be difficult to determine the fitness of a person for bail for a longer time. Whenever sufficient materials to clear the prima facie situation of the case to become available, there is a need to review the fitness of the accused, thereby, anticipatory bail should be for a limited period. In Gurbaksh Singh Sibbia v. State of Punjab Supreme Court expressed the opinion that it may be better than anticipatory bail should be given for a limited period till filing of FIR; after that accused should submit himself before the court and get the regular bail. In Salauddin Abdulsamad 
Shaikh v. State of Maharashtra ${ }^{2}$ anticipatory bail is given before the arrest of the person, only based on anticipation of arrest. Normally, the grant of bail is an issue to be decided by the trial court. Anticipatory bail cannot be used to by-pass the trial court. Therefore, ultimately matter of bail should be decided by the trial court, and for this purpose, anticipatory bail should be given for a limited period and then the person should take regular bail from the trial court. Further, anticipatory bail is granted at an early stage of investigation when the nature of the evidence may not be known; again it requires for grant of anticipatory bail only for a limited period and then the person should apply for regular bail. In this case, Court opined that anticipatory bail should be granted for a limited period, and on expiry of such period or the extended period regular court will deal with the matter based on progress in the investigation or charge-sheet submitted. In this case, Supreme Court was observing that anticipatory bail should be given for time necessary for moving the court for regular bail or extended period and the court has to decide about the grant of regular bail based on progress in the investigation or charge-sheet submitted by police officer In K L Verma v. State ${ }^{3}$ Supreme Court expressed the similar view but with some differences. In this case, Court gave observation that anticipatory bail is given in anticipation of arrest but the trial court should not be by-passed in granting of bail. Anticipatory bail should be given for a limited period and the court giving anticipatory bail should leave the matter to the trial court to determine in light of the evidence available in the progress of the investigation or after submission of the charge-sheet. Limited duration of anticipatory bail should be determined to give sufficient time to accused to move court for regular bail and to court to give sufficient time to determine bail petition. Supreme Court specifically observed that anticipatory bail may be granted for a duration that may extend to the date on which the bail application is disposed of or a few days thereafter to enable the accused person to move the higher court.

In the Gurbaksh Singh Sibbia case, Supreme Court expressed the opinion that anticipatory bail may be given for a longer period in the same manner as given in case of regular bail but it should be given for a limited period till filing of FIR; then after the accused should apply for regular bail. When Saladduin case and K L Verma case are compared; in both the cases Supreme Court was of opinion that in anticipatory bail granting trial court cannot be by-passed, ultimately matter relating to bail should be decided by the trial court and anticipatory bail can be given for limited period. In the Saladduin case, Court opined that the limited period is till period specified or extended period; here the court was specified the period to specific duration mentioned by the court granting anticipatory bail which is initially for a specified period or further on the application it may be extended for some more period. In the KL Verma case, Court expressed the opinion that anticipatory bail can be given for a limited period which is a period specified which may be extended till regular bail application is disposed of or few days thereafter to enable the accused person to move higher court. In Salauddin's case, a limited period of anticipatory bail was mentioned to extend up to the moving of bail application but in $K L$ Verma's case, a limited period of anticipatory bail was mentioned to extend up to moving of higher court in an appeal against the rejection of anticipatory bail petition. In Salauddin Case period was specified and also limited; with moving regular bail petition the anticipatory bail period comes to an end and by his submission through his regular bail petition accused has been submitted in custody and now by regular bail he may be released. In $K L$ Verma Case period of anticipatory bail extends up to moving of appeal petition, therefore, before the court considering regular bail accused is not in custody, thereby, it creates a legal issue that when a person is not in custody how he may be released on bail because bail is a release from the custody. Further, in the K L Verma Case, the limited period for anticipatory bail is not specified exactly, it has some indefinite situation regarding the period as up to move the higher court against the rejection of regular bail petition. In Naresh Kumar Yadav v. Ravindra Kumar ${ }^{4}$ Supreme Court expressed the opinion that a blanket order of anticipatory bail should not be passed, and if the protective umbrella of Section 438 is extended beyond what was laid down in Salauddin Shaikh Case the result would be clear bypassing of what is mandated in Section 439 regarding custody. Here Court was referring to the $K$ $L$ Verma Case decision that an anticipatory bail release extended up to moving of higher Court, then it will completely affect the whole concept of bail particularly provisions contained in Section 439 CrPC. For Section $439 \mathrm{CrPC}$ as it was interpreted in Niranjan Singh v. Prabhakar Rajaram Kharote ${ }^{5}$ without custody bail cannot be granted under Section 439 CrPC. In Naresh Kumar Yadav v. Ravindra Kumar, Supreme Court observed that an extended period up to moving higher court may cause requirements of Section 439 to become a dead letter, and no part of a statute can be rendered redundant in that manner.

In Gurbaksh Singh Sibbia v. State of Punjab blanket order reference was taken for anticipatory bail is given for not the specific case but as general protection available for many cases. Normally anticipatory bail protects a person against lodging in jail in a specific case. Anticipatory bail is protection to a person in a specific case. But when immunity against arrest is provided to a person against arrest, then it is blanket order and not permitted u/s $438 \mathrm{CrPC}$. a blanket order is an order for a case in general. In case the blanket order case is not much material thing, the order is given to the person; the case may be one or another case. In HDFC BankLtdv.J J Mannan@J M John Paul ${ }^{6}$ stricter view was taken that when anticipatory bail order is given for a longer period, then also it will be a blanket order. Anticipatory bail is given to protect the innocent person against lodging in jail during the investigation. But when the charge-sheet is filed, the person becomes charge-sheeted accused, his fitness for bail should be decided. Now charge-sheeted accused cannot take 


\section{Vol: 1, Issue: 4} December $/ 2020$

https://ijbssrnet.com/index.php/ijbssr DOI: $10.47742 /$ ijbssr.v1n4p1

benefit of anticipatory bail because anticipatory bail is given for the period of investigation and not for trial. If anticipatory bail continues to be available for trial also then it is blanket order. After becoming charge-sheeted accused, the person on anticipatory bail should submit himself before the court and obtain the regular bail. Supreme Court opined that the anticipatory bail should be given for a limited period only till the person gets regular bail from the court. In this case, the respondent was the Managing Director of a construction company engaged in the construction of Highways. The Company with collusion with another company took a loan of 2 Crore rupees from HDFC Bank to purchase some machinery but it was never purchased and the amount was misappropriated. Bank complained of offenses punishable u/ss 420, 467, 468, 471 and 120-B IPC. Respondent no. 1 filed an application in Madras High Court for the grant of anticipatory bail and it was granted. Bank filed an appeal before the Supreme Court for cancellation of anticipatory bail. Supreme Court modified anticipatory bail order of Madras High Court and directed respondent no. 1 to surrender before trial court forthwith and pray for grant of regular bail. In HDFC Bank Ltd v. J J Mannan @ J M John Paul Supreme Court observed:

"The object of Section $438 \mathrm{CrPC}$ has been repeatedly explained by this Court and the High Courts to mean that a person should not be harassed or humiliated to satisfy the grudge or personal vendetta of the complainant. But at the same time, the provisions of Section $438 \mathrm{CrPC}$ cannot be invoked to exempt the accused from surrendering to the Court after the investigation is complete and if a charge-sheet is filed against him. Such an interpretation would amount to violence to the provisions of Section $438 \mathrm{CrPC}$, since even though a charge-sheet may be filed against an accused and a charge is framed against him, he may still not appear before the court at all even during the trial... Once the investigation makes out a case against him and he is included as an accused in the charge-sheet, the accused has to surrender to the custody of the court and pray for regular bail..."

Consideration for anticipatory bail and regular bail differs; successful anticipatory bail may be one important matter to consider that person may be fit for regular bail but a person on anticipatory bail may not be necessarily fit for regular bail. In Satpal Singh v. State of Punjab ${ }^{7}$ Supreme Court observed:

"In any case, the protection under Section $438 \mathrm{CrPC}$ is available to the accused only till the court summons the accused based on the charge sheet (report under Section 173 (2) CrPC). On such appearance, the accused has to seek regular bail under Section $439 \mathrm{CrPC}$ and that application has to be considered by the court on its own merits. Merely because an accused was under the protection of anticipatory bail granted under Section 438 CrPC that does not mean that he is automatically entitled to regular bail under Section $439 \mathrm{CrPC}$. The satisfaction of the court for granting protection under Section 438 CrPC is different from one under Section 439 CrPC while considering regular bail."

In Satpal Singh v. State of Punjab appellant filed an anticipatory bail petition before Punjab and Haryana High Court and requested anticipatory bail direction based on parity that in the same case the coordinate bench of same High Court had granted anticipatory bail direction to his brother and father, the co-accused. Appellant was accused in a case for offense punishable u/ss 22 and 29 Narcotics Drugs and psychotropic Substances Act (NDPS Act); he was alleged for running drug peddling along with his father and brothers. In a raid, large quantities of prohibited drugs were recovered from their possession. High Court rejected his petition and observed that bail matter under NDPS Act is determined in light of Section 37 of NDPS Act, thereby, to co-accused also anticipatory bail could not be granted, the coordinate bench had not taken limitation $\mathrm{u} / \mathrm{s}$ 37 NDPS Act. Section 37 NDPS Act is a specific provision that prescribes the special procedure for bail in case of some offenses punishable by the NDPS Act. Due to Section 4 (2) CrPC Section 37 NDPS Act prevails over provisions relating to bail contained in CrPC. Under Section 37 NDPS Act when a person is accused of an offense punishable $\mathrm{u} / \mathrm{s} 19$ or 24 or $27-\mathrm{A}$ and also for offenses involving commercial quantity, he shall not be released on bail unless Public Prosecutor has been given an opportunity of hearing; on such hearing, the court is satisfied that there is reasonable ground for believing that the person is not guilty of the alleged offense and that he is not likely to commit any offense while on bail. These limitations are in addition to those prescribed under the CrPC or any other law for time being in force on the grant of bail. High Court considering Section 37NDPS Act decided that to in favor of accused anticipatory bail direction cannot be passed. Appellant challenged the decision of the High Court filed an appeal before the Supreme Court. Supreme Court accepted the view of the High Court and issued direction to State for taking initiative for cancellation of anticipatory direction in favor of co-accused.

\section{Anticipatory bail direction does not make arrest stay}

In Adri Dharan Das v State of W. Bengal ${ }^{8}$ Supreme Court cleared that anticipatory bail direction is the direction for release on bail in case of arrest of a person in whose favor it has been issued, therefore court granting anticipatory bail cannot make arrest stay with anticipatory bail. In this case, there was a dispute between the present and former presidents of the Calcutta branch ISKCON and as result, many civil cases were pending between them. Present president filed a petition before Magistrate us 156 (3) $\mathrm{CrPC}$ alleging former president and five others for the commission of various offenses u/ss 406, 467, 468, 471 and 420 IPC. Magistrate referred the matter to the police station for investigation. Calcutta High Court granted anticipatory bail to two accused persons but refused to the appellant, the former president of Calcutta branch ISKCON. The Appellant filed an 
https://ijbssrnet.com/index.php/ijbssr DOI: 10.47742/ijbssr.v1n4p1

appeal before the Supreme Court and requested for grant of anticipatory bail. Supreme Court upheld the decision of the Calcutta High Court. The court directed that if a bail petition is filed before the Magistrate $\mathrm{u} / \mathrm{s} 437 \mathrm{CrPC}$, he has to dispose it on the same day, and if filed before Session Judge $\mathrm{u} / \mathrm{s} 439 \mathrm{CrPC}$, it has to be disposed of as early as possible. In this case, one issue was relating to arrest stay during the pendency of anticipatory bail petition; Supreme Court observed:

"Ordinarily, an arrest is a part of an investigation intended to secure several purposes. The accused may have to be questioned in detail regarding various facets of motive, preparation, commission, and aftermath of the crime and the connection of other persons, if any, in the crime. There may be circumstances in which the accused may provide information leading to the discovery of material facts. It may be necessary to curtail his freedom to enable the investigation to proceed without hindrance and to protect witnesses and persons connected with the victim of the crime, to prevent his disappearance, to maintain law and order in the locality. For these or other reasons, an arrest may become an inevitable part of the process of investigation. The legality of the proposed arrest cannot be gone into in an application under Section 438 of the Code... an interim order restraining arrest, if passed while dealing with an application under Section 438 of the Code will amount to interference in the investigation, which cannot, at any rate, be done under Section 438 of the Code."

The arrest is a very important aspect of criminal justice; for satisfying various requirements and purposes, the arrest is an important measure. By arrest, a person is taken into custody, and thereby, effective investigation particularly custodial investigation, prevention of repetition of crime, the safety of evidence, cooperation and participation in criminal proceeding and availability for conviction and sentence are ensured, and further, the ultimate goal of criminal justice to tackle the problem of crime, criminal and criminality is strived to be achieved. Even when a person is released on bail, his fitness regarding aforesaid is ensured and term and conditions are imposed, surety and security are taken. Hereby arrest serves an important and crucial purpose. An arrest cannot be prohibited or stayed in granting anticipatory bail. Provisions contained in Section 438 (1) and 438 (3) CrPC clears that arrest cannot stay in this Section, and further, the arrest is necessary for anticipatory bail to become operational. Always anticipatory bail is given before arrest; before the arrest, it remains mere direction to grant bail, as soon as the person is arrested, it becomes operational and direction to bail now results in a release on bail. anticipatory bail does not prohibit arrest but about arrest, it is provided, in another way it may be taken that anticipatory bail permits arrest anticipatory bail prohibits custody particularly continuance of custody. In $D K$ Ganesh Babu v. P T Manokaran ${ }^{9}$ Court reiterated and more specified that arrest stay is not permissible u/s $438 \mathrm{CrPC}$. In this case, a complaint was filed alleging due to a dowry demand made by respondent no. 1 to 3 , the victim committed suicide. Accused no. 1 to 3 fearing arrest in the case for offenses punishable u/ss 304-B IPC and Section 4 Dowry Prohibition Act, applied for anticipatory bail before the Madras High Court. In this case, Single Judge of Madras High Court passed direction that petitioners shall give appear before the Metropolitan Magistrate and execute bond furnishing sureties and securities. They were directed to report to the police officer and to cooperate in the investigation. The order was challenged before Supreme Court on the ground that it was violative to Section $438 \mathrm{CrPC}$; bail is granted without surrender. In the order, the High Court indirectly created a bar on the arrest. The accused person did not come in custody as they did not surrender, and further, they were not arrested. They were reported to the police officer but they cannot be arrested as they were already on bail. Furthermore, the directs of the High Court were completely protecting them against the arrest. Supreme Court allowed the appeal and directed respondent-accused persons to surrender before the concerned court and move bail petition u/s $439 \mathrm{CrPC}$ and the court was directed to consider bail according to law. In this case, the Supreme Court observed:

"The direction which a Court can issue under Section 438 of the Code is that in the event of arrest of $n$ accused on an accusation of committing a non-bailable offense, he shall be released on bail subject to such conditions as the Court may deem fit to impose. An application under Section 438 of the Code can be moved only by a person who has not already been arrested. Once e is arrested, his remedy is to move the concerned Court either under Section 437 or Section 439 of the Code. In the very nature of the direction which the Court can issue under Section 438 of the Code, it is that the direction is to be issued only at the pre-arrest stage. The direction becomes operative only after the arrest. The Condition precedent for the operation of the direction issued is the arrest of the accused. This being so, the irresistible inference is that while dealing with an application under Section 438 of the Code the Court cannot restrain arrest." 10

With the passing direction of anticipatory bail High Court or Court of Session may impose such conditions as it thinks fit in the light of facts of a particular case. Usually, when anticipatory bail direction is issued, the case is at the investigation stage particularly at the initial stage of the investigation, therefore, the need arises that such measures should be taken by which effective investigation should not be affected. In this regard, Court imposes various conditions for effective investigation, protection of evidence and witnesses, and prevention of abscondance. Some conditions are explicitly enumerated in Section 438 (2) CrPC. Conditions mentioned in sub-section (2) of Section 438 CrPC are examples; those conditions or other conditions may be imposed on Court based on the fact of the case concerned. Section 438 (2) CrPC mentions 
https://ijbssrnet.com/index.php/ijbssr DOI: 10.47742/ijbssr.v1n4p1

the following conditions which may be imposed with passing anticipatory bail direction:

1. The person shall make himself available for interrogation by a police officer as and when required.

2. The person shall not tamper with evidence or terrorize witnesses.

3. The person shall not leave India without the previous permission of the Court.

4. The court may impose any other condition which it may impose u/s 437 (3) CrPC.

In Gurbaksh Singh Sibbia v. State of Punjab Supreme Court considered about condition imposition power of High Court and Session Court in case of anticipatory bail and opined that the courts should have the freedom to determine about conditions imposed; the express condition cannot delimit ambit of condition determination but it should be decided according to the requirement of case concerned, therefore condition may vary from case to case. in this case Supreme Court observed:

"This is not to say that anticipatory bail if granted, must be granted without the imposition of any conditions. That will be contrary to the very terms of S. 438. Though subsec. (1) of that section says that the Court "may, if it thinks fit" issue the necessary direction for bail, sub-sec. (2) confers on the Court the power to include such conditions in the direction as it may think fit in the light of the facts of the particular case, including the conditions mentioned in Cls. (i) to (iv) of that subsection. Controversy, therefore, is not whether the Court has the power to impose conditions while granting bail. It clearly and expressly has that power. The true question is whether by a process of construction, the amplitude of judicial discretion which is given to the High Court and the Court of Session, to impose such conditions as they may think fit while granting anticipatory bail, should be cut down by reading into the statute conditions which are not to be found therein, ... the High Court and the Court of Session to whom an application for anticipatory bail is made ought to be left free in the exercise of their judicial discretion to grant bail if they consider it fit so to do on the particular facts and circumstances of the case and on such conditions as the case may warrant..."

Anticipatory bail is a completely different kind of bail direction; it is issued before the arrest and custody. Anticipatory bail is issued for grant of bail on a future date when the person is arrested, hereby, bail is not presently granted but granted for a future date; presently fitness for bail is decided that on a future date when the person will be arrested, he will be fit for bail and he shall be released on bail. Anticipatory bail becomes operational with the arrest of the person; arrest act like a trigger for anticipatory bail to become operational. Anticipatory bail does not put a bar on the arrest but prohibits keeping a person in custody. Anticipatory bail is different from regular bail. Regular bail is granted after arrest and custody; it means regular bail is granted while a person is in custody. Regular bail is presently granted and immediately person in custody is released on his execution of requisite bonds and furnishing required surety and security.

Section 438 (2) CrPC specifically and expressly clears that with anticipatory bail concerned court may impose conditions also. Supreme Court in Gurbaksh Singh Sibbia case settled the law that courts have judicial discretion to grant anticipatory bail and further have judicial discretion to determine and impose conditions; courts may impose some other conditions besides express conditions mentioned in Section 438 (2) CrPC based on fact and circumstances of the case, thereby, conditions may vary from one case to another. In Munish Bhasin v. State (Government of NCT of Delhi) ${ }^{11}$ Supreme Court decided that conditions imposed by courts with anticipatory bail directions must be related to bail; conditions which have no reference to bail cannot be imposed. In this case, the wife of the appellant filed a complaint against him and his parents alleging commission of offenses u/ss 498-A and $406 \mathrm{r} / \mathrm{w} 34$ Indian Penal Code (hereinafter referred to as IPC). The Appellant and his parents moved Delhi High Court for grant of anticipatory bail directions. High Court granted anticipatory bail and as a condition to anticipatory bail directed to pay Rs. 12500 per month as maintenance to wife and child. Further, a single Judge of High Court was directed to pay arrear of this maintenance amount (Rs. 300000) within six months. Appellant-accused challenged condition of anticipatory bail to pay maintenance and arrear of maintenance. Supreme Court decided that High Court and Session Court with anticipatory bail direction, may impose condition but irrelevant conditions cannot be imposed. Conditions imposed under Section 438 of the Code cannot be harsh, onerous, or excessive to frustrate the very object of the grant of anticipatory bail. The matter relating to maintenance is to be decided by a competent court in an appropriate proceeding. Supreme Court allowed the appeal and set aside condition relating to the payment of maintenance and arrear of maintenance. In this case, the Supreme Court observed:

"It is well settled that while exercising discretion to release an accused under Section 438 of the Code neither the High Court nor the Session Court would be justified in imposing freakish conditions. There is no manner of doubt that the court having regard to the facts and circumstances of the case can impose necessary, just, and efficacious conditions while enlarging an accused on bail under Section 438 of the Code. However, the Accused cannot be subjected to any irrelevant condition at all."

At the time issuing anticipatory bail direction, the court may impose conditions and direct for cancellation of anticipatory bail in case of non-observance of such condition but it is necessary that conditions imposed must be relevant to anticipatory; irrelevant conditions cannot be imposed. In Kunal Kumar Tiwari alias Kunal Kumar v. State of Bihar ${ }^{12}$ respondent 


\section{Vol: 1, Issue: 4}

December $/ 2020$

https://ijbssrnet.com/index.php/ijbssr DOI: 10.47742/ijbssr.v1n4p1

no. 2 lodged a case in police station against her husband for dowry demand and physical and mental torture. The case was registered u/ss 498-A, 341, 323, 379, 506, 34 IPC, and 3, 4 Dowry Prohibition Act. Accused-appellant, the husband, apprehending his arrest, moved a petition before the High Court for grant of anticipatory bail. High Court passed the order for grant of anticipatory bail but Supreme Court found that direction and conditions were not by legal provisions. High Court directed that petitioner to surrender along with wife before SDJM within four weeks from passing of such order. SDJM on the satisfaction that husband was ready to keep wife with full dignity and care but the wife does not want to go with him or both parties adamant to live separate and want s divorce on mutual consent u/s 13-B Hindu Marriage Act, then SDJM will release the petitioner on a provisional bail for one year and SDJM will monitor the relationship between the parties by calling both of them every three months; in such monitoring when SDJM finds that good conjugal rights have been restored and wife does not complain about physical and mental torture or conjugal right cannot be restored due to indifferent behavior of wife or both parties agreed to live separate and take divorce with mutual consent, then SDJM will confirm the provisional bail. Husband filed an appeal before the Supreme Court against the order of the High Court. In Section $438 \mathrm{CrPC}$ or any provision of CrPC such bail direction is not mentioned and further such conditions are in no way related to bail. Bail is granted based on the fitness of the accused of bail. In this direction fitness of the accused for bail was not considered. What were directions to be fulfilled for getting bail, only because of the problem in that reference this criminal case was between husband and wife? When a person will surrender before SDJM, how it will be anticipatory bail; anticipatory bail is granted before custody, by surrendering accused will come in custody. After custody regular bail is granted. in regular bail or anticipatory bail, there is no provision for grant of provisional bail. Supreme Court set aside conditions and made provisional bail order as confirm bail order. Supreme Court observed that the conditions were onerous and absurd. These conditions are alien and cannot be sustained, thereby, such conditions cannot be imposed. Supreme Court observed in this case:

"Coming back to the case at hand, from the perusal of the impugned order it is clear that the court exceeded its jurisdiction in imposing such arbitrary conditions. Some of the conditions imposed are highly onerous and are absurd. Such onerous anticipatory bail conditions are alien and cannot be sustained in the eyes of law. The conditions imposed appear to have no nexus with the good administration of justice or advancing the trial process, rather it is an over-zealous exercise in utter disregard to the very purpose of the criminal justice system."

In Bhadresh Bipinbhai Sheth v. State of Gujarat $^{13}$ accused and complainant were neighbors. The complainant, the prosecutrix, wrote a complaint letter on
29.5.2001 to ACP, Crime Branch, Ahmedabad City, in which she made an allegation on accused of her harassment. After two days the police officer from the concerned police station recorded her statement. In this recorded statement there was no allegation of rape committed by the accused. She made allegations for the commission of maltreatment, blackmail, etc. based on this recorded statement FIR was lodged. The charge was framed for an offense punishable $\mathrm{u} / \mathrm{s} 506$ (2) IPC and trial initiated in the year 2001. In the year 2010 prosecutrix applied the addition of a charge for an offense punishable u/s 376 IPC. Metropolitan Magistrate directed police for special investigation $\mathrm{u} / \mathrm{s} 173$ (8) CrPC. it was challenged by parties to the case and the matter went up to the Supreme Court, which upheld the direction of Magistrate. Ultimately police officer submitted a charge-sheet stating for prima facie establishing of case $\mathrm{u} / \mathrm{s} 376$ IPC. Magistrate initiated process for committal proceeding. Accused applied to Session Court for anticipatory bail which was granted on 18.5.2013. Prosecutrix challenged anticipatory bail order before the High Court. High Court canceled anticipatory bail. Accused challenged the cancellation order passed by the High Court before the Supreme Court. Supreme Court found that the allegation of rape goes back to years 1997-1998, 2001 prosecutrix wrote a letter to ACP in that she alleged rape but when she filed FIR allegation for rape was missing. During the investigation, after filing of charge-sheet, during cognizance, at charge framing, never prosecutrix protested for the inclusion of allegations for rape. Only in 2008, she put objection and it was about 7 years after framing of charge in the case for offense $\mathrm{u} / \mathrm{s}$ 506 (2) IPC and in 2010 she moved an application for adding a charge for an offense punishable u/s 376 IPC. Supreme Court opined that when there is such delay, the allegation of rape pertains to the period about 17 years ago, from charge framing prosecutrix moved court after 9 years to add a charge for rape and charge for rape punishable u/s 376 IPC was added in 2014, in such situation, there is no reason why the appellant should not be given the benefit of anticipatory bail. Further Court opined that merely because the charge under Section 376 IPC, which is a serious charge, is now added, the benefit of anticipatory bail cannot be denied when such a charge is added after a long period. During the whole proceeding taking place since 2001, never accused created any problem and always he participated in proceedings. Whenever the accused may create any problem, an application for cancellation of bail may be made before the trial court and the trial court may pass the order following the law. Supreme Court observed that in granting anticipatory bail, a balance has to strike between two factors, namely, no prejudice should be caused to free, fair, and full investigation, and there should be the prevention of harassment, humiliation, and unjustified detention of the accused. In consonance with legislative intention, the grant or refusal of anticipatory bail should necessarily depend on the facts and circumstances of each case. Supreme Court set aside the order of the High Court and 
https://ijbssrnet.com/index.php/ijbssr DOI: $10.47742 /$ iibssr.v1n4p1

upheld the anticipatory bail order passed by the Court of Session.

Offenses against women particularly sex offenses are increasing in rate and brutality which compels the criminal justice system to create new measures to tackle the problem effectively. In this connection in 2013 and 2018 major amendments were made in criminal law to provide sufficient provisions for necessary and effective actions against sex crimes and criminals committing such crimes. By Criminal Law (Amendment) Act 2018 sub-section (4) was added in Section 438 which directs that anticipatory bail shall not be available to a person who has reason to suspect that he may be arrested on accusation of commission of an offense punishable $\mathrm{u} / \mathrm{s} 376$ (3) or $376 \mathrm{AB}$ or $376 \mathrm{DA}$ or 376 DB of Indian Penal Code. Section 438 (4) CrPC provides:

"Nothing in this section shall apply to any case involving the arrest of any person on an accusation of having committed an offense under subsection (3) of section 376 or section $376 A B$ or section $376 D A$ or section $376 D B$ of the Indian Penal Code."

\section{Concluding remarks}

Anticipatory bail is a completely different kind of bail granting and providing protection to a person but such matter comes at the very beginning of the case particularly when an investigation has just initiated or even it may happen that FIR itself may not have been lodged. Therefore, what are general requirements for determination of fitness of a person for bail may not be sufficiently available like availability and nature of evidence, nature of the crime, impact of crime on victim and society, etc; in such a situation determination of fitness of person requesting for anticipatory bail may not be an easy task. Further, in the investigation, one main measure, on which usually effective investigation depends, is the custodial investigation. In case of anticipatory bail, with arrest anticipatory bail becomes operational and the person does not continue in the custody, and thereby, in case of grant of anticipatory bail, the custodial investigation may not be available to the police officer. Keeping in view these aspects, anticipatory bail is not a simple order but with care and caution decision should be taken by courts for granted. Anticipatory bail order is extra-ordinary power but it does not mean that applicant has to make his case as a special case for getting anticipatory bail direction. If such a requirement would be made compulsory, the consequence of such requirement will be making provisions of Section $438 \mathrm{CrPC}$ completely inefficacious and practically unavailable to any person. The main purpose of anticipatory bail is to protect the innocent person from humiliation and harassment suffered due to keeping in custody without sufficient cause and rational reason. But anticipatory bail cannot take place of regular bail. When anticipatory bail is granted lesser materials in the case may be available, the investigation may be at the initial stage, therefore on such considerations determination for bail for a longer period may not be appropriate. It may be better that there should be reconsideration for the continuance of bail. Therefore, nowSupreme Court is of opinion to grant anticipatory bail for a limited period that is up to the filing of charge-sheet or after the filing of charge-sheet when accused is summoned; the person on anticipatory bail should surrender before court and request for grant of regular bail.

\section{References \\ Cases:}

Gurbaksh Singh Sibbia v. State of Punjab 1980 CrLJ 1125

Salauddin Abdulsamad Shaikh v. State of Maharashtra AIR 1996 SC 1042

K L Verma v. State (1998) 9 SCC 348

Naresh Kumar Yadav v. Ravindra Kumar AIR 2008 SC 218

Niranjan Singh v. Prabhakar Rajaram Kharote AIR 1980 SC 785

HDFC Bank Ltd v. J J Mannan @ J M John Paul AIR 2010 SC 618

Satpal Singh v. State of Punjab AIR 2018 SC 2011

Adri Dharan Das v State of W. Bengal (2005) 4 SCC 303

D K Ganesh Babu v. P T Manokaran AIR 2007 SC 1450

Munish Bhasin v. State (Government of NCT of Delhi) (2009) 4 SCC 45

Kunal Kumar Tiwari alias Kunal Kumar v. State of Bihar AIR 2017 SC 5416

Bhadresh Bipinbhai Sheth v. State of Gujarat AIR 2015 SC 3090 